\title{
DECISION MAKING EXAMPLE FOR ON-BOARD DISTRESS SiTUATION BASED ON AGENTS
}

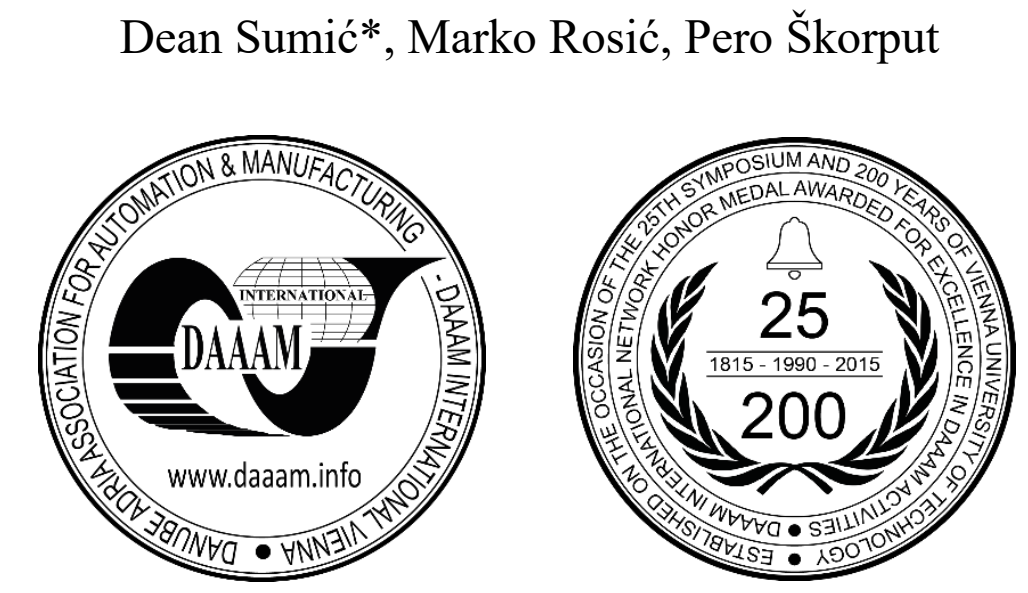

This Publication has to be referred as: Sumic, D[ean]; Rosic, M[arko] \& Skorput, P[ero] (2018). Decision Making Example for On-Board Distress Situation Based on Agents, Proceedings of the 29th DAAAM International Symposium, pp.0553-0558, B. Katalinic (Ed.), Published by DAAAM International, ISBN 978-3-902734-20-4, ISSN 1726-9679, Vienna, Austria

DOI: $10.2507 / 29$ th.daaam.proceedings.080

\begin{abstract}
There is a high risk of accidents onboard ships despite the implementation of technologically advanced subsystems whose basic function is protecting people and reducing material damage. Research of human error analysis indicate that human factor substitution with program agents can achieve significant improvements in decision-making processes in distress ship situations. This research will carry out a functional analysis of ship's distress situations and analysis of available agent technologies. By means of analyses input indicators will be identified according to which appropriate types of program agents will be selected. According to the preselected agent technology, a decision model will be developed in the selected class of distress ship's situations.
\end{abstract}

Keywords: human error; agent technology; distress situations; modelling; environment objects; autonomous ship

\section{Introduction}

Incident traffic management is a functional area of Intelligent Transport Systems - ITS and is closely related to traffic management. The management of distress situations within maritime traffic management is a subcategory or class of incident traffic management situations that directly threaten human lives and should be part of technology and management strategy to increase maritime traffic safety.

The International Maritime Organization (IMO) has defined Maritime Communications within International Convention for Safety of Life at Sea (SOLAS) in Chapter IV. Radio communications are mandatory onboard all SOLAS ships and organised by the Global Maritime Distress and Safety System (GMDSS) [1]. In the proposed scientific study, human factor substitution is considered in the decision-making process for distress ship situations by using the agents. Agents are used to automate certain procedures and processes and they are capable of autonomously receiving information from the environment, acting within their environment, and executing set of tasks for which they are anticipated.

Agents are often used to perform tasks that are difficult for humans to perform or perform consistently. The agent's application excludes human errors that may arise in decision-making in stressful situations, and the distress situations are exactly like this. 


\section{Previous research}

Researchers have focused on several different areas: from a systems approach to risk analysis of maritime operations [2], to new hybrid approaches to human error probability [3]. Modern ships and ship systems are technologically advanced and highly reliable. Reliability of marine systems is increasing and the maritime industry builds ships with improved hulls, separate engine rooms, trained and educated crews, in order to protect crews and passengers and reduce material costs [4]. For greater productivity and efficiency, improvements are a permanent goal in the maritime industry and the IMO. The ship's hull, ship stability systems, ship propulsion systems, navigation equipment and the high standards of seaman training are constantly being improved [5].

The construction of the ship and the equipment of the ship is continuously checked from the construction itself to the exploitation and developed standards and classification societies that provide for the purpose of preserving life, property and the environment. [6] Despite the above mentioned, the rate of maritime incidents is still significant, and despite the technology applied so far in various ships subsystems, risk of accidents has not been significantly reduced. The essential reason for this fact is that the ship as a system involves people as elements of the system [7]. Present rules for ships with crew are going to be reconstructed to fulfil requirements for autonomous ships by classification societies [6] as well as legal issues. Human error has a significant impact on maritime incidents, significant number $76 \%$ to $96 \%$ of incidents, at least partially, are affected by some kind of human error [8]. Marine incidents classified by events amount to 84-88\% tanker incidents, 79\% groundings, 89-96\% collisions, 75\% collisions with static objects, and 75\% fire and explosion. Safety Science has developed a Human Factor Analysis and Classification System (HVACS) to determine the role of the human factor in marine incidents [9] or hybrid models in order to prevent material damage and save human lives [10]. Faults in complex systems caused by the human factor are categorized by determining the category of human error [11]. Studies have shown that maritime incidents are a random occurrence with a low probability, the outcome of which can be predicted by the prediction model [12] or the probability of a human error can be predicted by analysis using the

Cognitive Reliability and Error Analysis Method (CREAM) and evidence-based decision-making mechanisms [13]. The maritime industry has developed a number of measures to raise the level of safety and reduce the impact of human factors. Maritime Resource Management (MRM) standardized training was introduced, the application of the International Safety Management Code (ISMC) and the International Convention on the Training of Seafarers (International Convention on Standards of Training, Certification and Watch keeping for Seafarers - STCW) by the IMO. Researches have demonstrated human factor dependence in various distress situations such as collisions [14], listing [15] or fire [16]. The methodology of a hybrid multi-criteria approach to decision making can be used to investigate maritime incidents resulting from human error [17]. From the above data on the impact of human factors in incident situations, it is evident that an important step forward in reducing the human factor's influence can be made by human substitution; first as partial substitution of the human factor and ultimately complete human factor substitution with more reliable solutions. As an area of demand for such a solution, the application of Information and Communication Technology (ICT) is imposed on the diagnosis of human-operator behaviour errors [28].

Maritime communications and maritime e-navigation are based on ICT required for Integrated Operations of Ships while reducing crew numbers [18]. The name of integrated ship operation refers to the integration of people, work processes and technology in order to better decide and execute [19] based on the frequent acquisition of real-time data and enabling efficient joint-action. Crew and officers lack of attention, false assumptions and bad habits, lack of training and negative personality cause $93 \%$ of ship incidents [11]. In order to reduce the number of human-induced incidents, researchers have used various simulators for additional shipboard officer training to reduce crew risks [20] and even the soft models can be used to develop a human reliability model [27]. Agents are systems that have the characteristics of autonomy, or have the ability to act without the direct intervention of the user or some component of the computer system and have control over their actions. Agents have the ability to communicate with other agents or with the user and possess the ability to reactivity where they perceive their environment. In order to accomplish their task, agents are not only responsive to changes in the environment, but are able to take the initiative by initiating changes in the environment, that is, they have a proactive character [21].

An agent can be defined as a program or software that works independently and is capable of imitating social interaction and can perform tasks in a proactive or reactive way. From this definition of agent comes also Agent Oriented Modelling (AOM) [22]. AOM is one of the agent-based methodology to be used for the development of agent-based systems. The knowledge that an agent possesses is divided into social knowledge and conceptual knowledge [23]. An agent's social knowledge is his knowledge of ways to collaborate with the environment. This includes cooperation with all elements of the environment, as well as with other agents who may be in the environment. Such systems where there are several agents working together to achieve common goals are referred to as Multi Agent Systems MAS [24].

Traffic and transportation systems consist of a large number of autonomous and intelligent entities that aim to perform certain transport tasks. MAS enables simulation modelling of transport systems as they provide an intuitive environment for describing each autonomous entity at an individual level. In such a multi-agent simulation environment, any intelligent traffic entity can be modelled as an agent with its conceptual knowledge [25]. Such conceptual knowledge includes the goals of the agents, the actions an agent can do, and the knowledge of the environment resources available to the agent $[21]$. 


\section{Problem explained}

Onboard ship machinery spaces are the most exposed to danger of fire. Places where fuel, electricity, sea water, oil and ignition come together is definition of danger itself. For modelling purposes ship spaces are firstly identified as shown in Fig. 1. Possible places for fire extinguishing are divided in accommodation, cargo or machinery spaces.

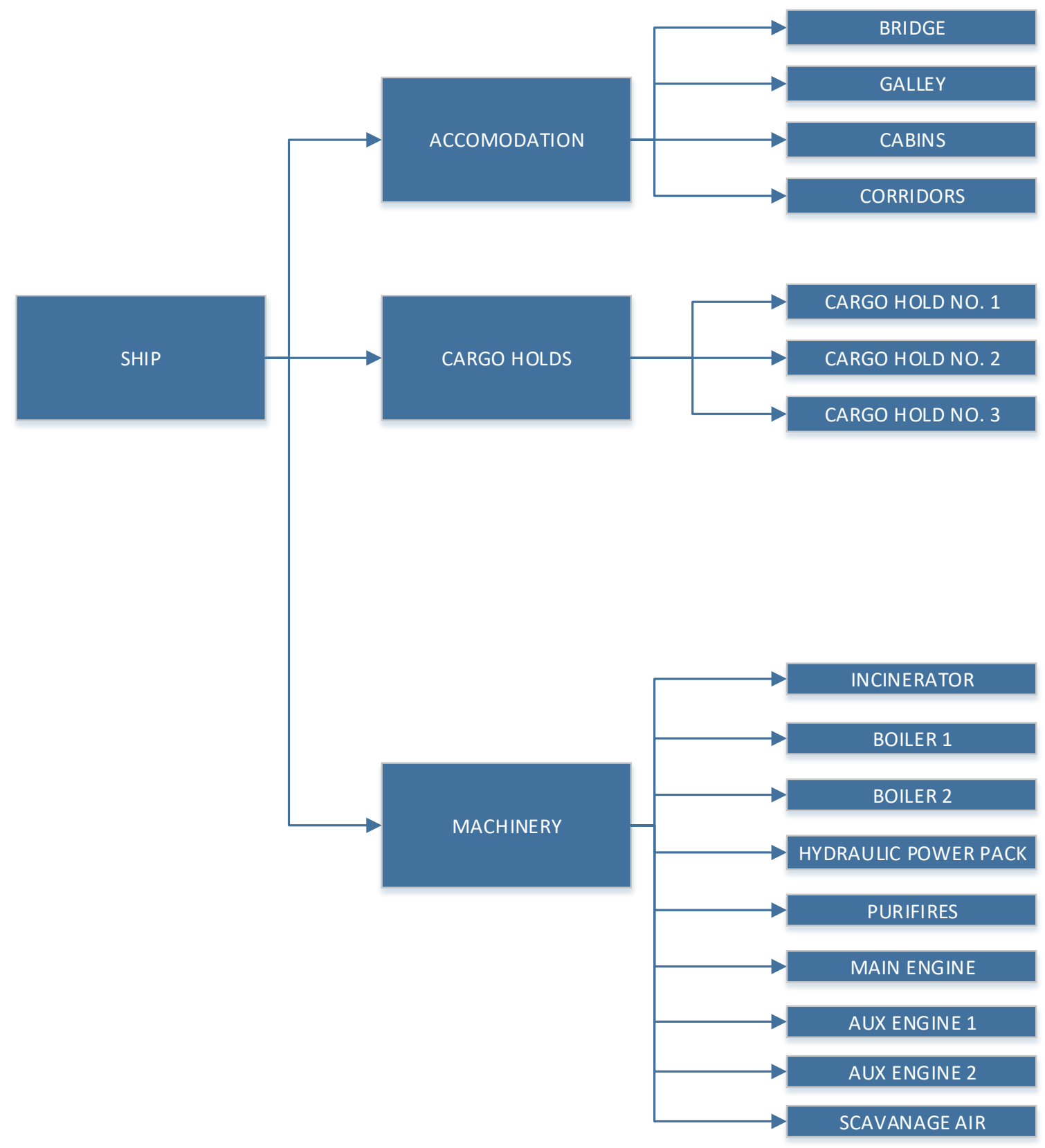

Fig. 1. Ship spaces resolved

Ship spaces shown in Fig. 1 were designed in shipyard with pre-built fire alarm system to detect various types of fire. Those alarms produces sound and visual alarms that will inform crew about fire in those fire zones by using addressable alarms sockets that mark exact point of fire danger in graphical way on the map. Shipyards design provides equipment for fire extinguishing that crew will use if needed.

Time to act on site with fire extinguishing equipment is calculated in initial design of equipment and data is provided from fire extinguishing manufacturer. What is not calculated and what can go wrong is human impact. In present fire systems, humans are those who actually do fire extinguishing in all systems besides areas with sprinkler systems. Crew is needed to estimate alarms given from alarm system, to take proper suits, helmets, breathing and other safety apparatus prior to going on site to estimate fire and start extinguishing procedures. 


\section{Technical proposal}

It is necessary to consider the pros and cons of today available agent-based paradigm and appropriate technologies to be appropriately selected by one agent-based technology that optimally suits for research. Within these activities, a comparative analysis method needs to consider the types of agents, the ways in which agents store their own states and knowledge, standardized ways of interacting with one another, and ways of communicating with the environment.

Within the analysis of the agent's communication with the environment, one should also consider the ways of a clear and fast communication agent-human, because this kind of communication is expected to be needed in achieving the goals of this work. Special emphasis is being placed on multi-agent systems in a dynamic environment because it is expected that such systems will be the optimal choice for solving the problem within the ABM simulation environment. In accordance with the selection of appropriate types of decision-makers in ship-distress situations it is necessary to synthesize the achieved results in order to achieve the optimal platform (agent type, agent development environment, communication language, know-how) the scientific contributions of this research. Due to programming simplicity Netlogo programming language was used to achieve workspace for receiving testbed environment. Among various tools that can be used for used for ABM [26], Netlogo has been chosen due to its simplicity used for modelling. Another plus is that it is open source freely available from NetLogo website with growing community and comes with prebuild library of example models with code and instructions how to use them.

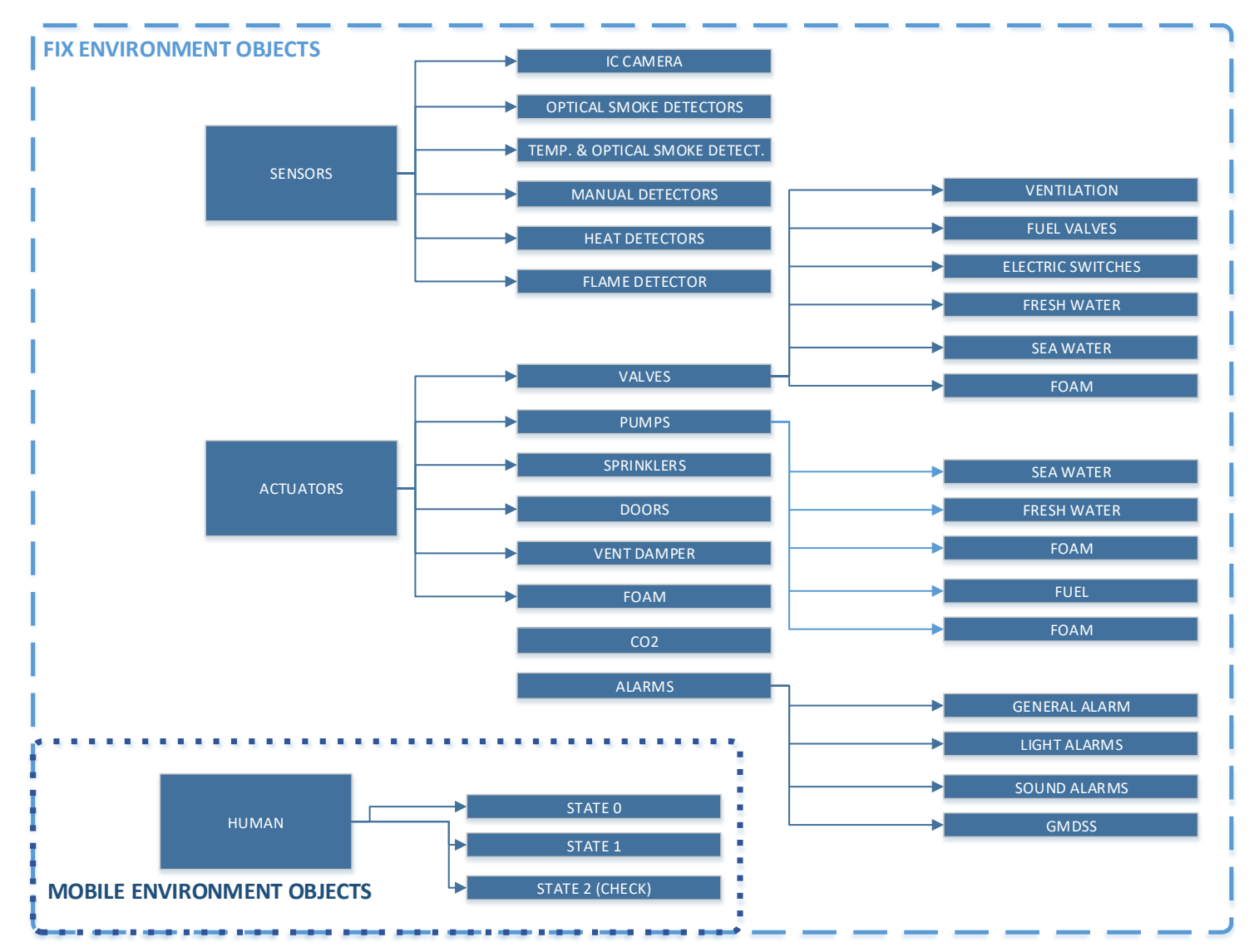

Fig. 2. Environment objects identified

For modelling purposes it is needed to put model in suitable environment and to identify object in that environment. In Fig. 2 necessary object identification is made and that objects were needed for modelling.

One example is given where alarm indicates fire in machinery spaces boiler room. That space is designed to be filled with foam in case of fire as presented in Fig. 3. Agent technology which is engaged in proposed solution to deal with fire in machinery spaces will do fire extinguishing in simulation.

Time needed for crew to come on assembly station in completely avoided. Speed of fire propagation, or calculation of number of foam generators can be done by means simulation. Valves representing closing of ventilation, electrical power or fuel can be easily put in open or closed position to check simulation experiment outcome. Other fire extinguishing media besides foam can be easily put in simulation environment such as CO2 gas. First crew must escape, then fire doors must be sealed, as well as ventilation and power electricity shut off and then gas can be flushed into fire space. 


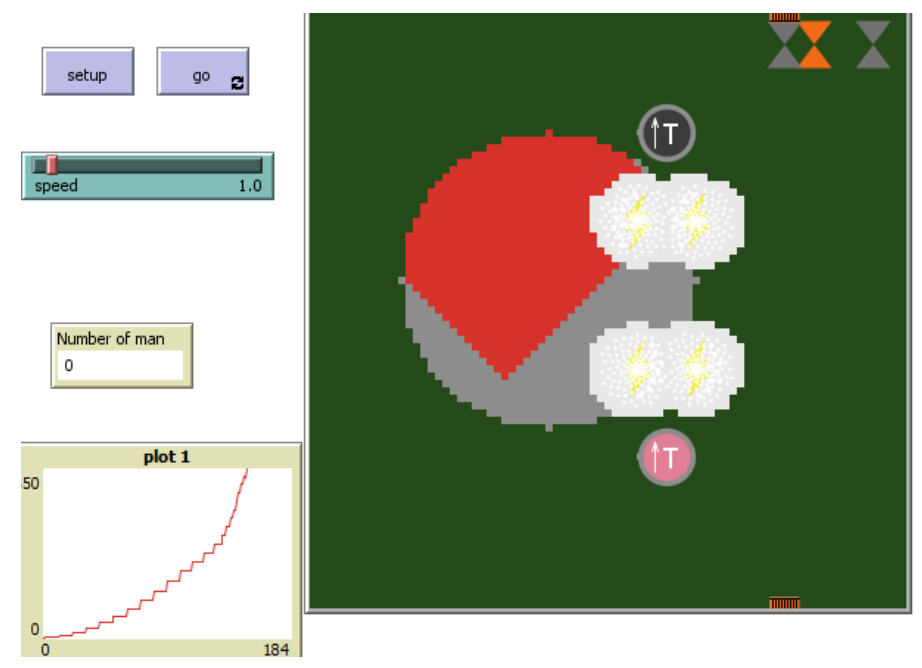

Fig. 3. NetLogo simulation experiment of boiler room

\section{Conclusions}

- Although present onboard rules prerequisite crew for distress situations, AI can contribute better solutions.

- Fire example was taken for modelling purposes of a distress situation.

- Agent technology is suitable solution to eliminate human error impact on fire extinguishing in various spaces onboard ships and despite limitations of used model, it can be used for building own platform for doing more complex analysis.

- Time needed for crew to get on assembly station in completely avoided as well as "panic driven" human solutions. Simulation can be run as many times as needed to take new conclusions.

- Researcher had measured that human errors can occur in up to $33 \%$ cases, when man machine interface is used. AI system will not do errors in that high percentage in any circumstances if programming is well made.

- For further research it can be modelled to deal with fire in more than one machinery space simultaneously. Several fire extinguishing systems for various simulations can be added.

\section{References}

[1] GMDSS manual: Manual of the Global Maritime Distress and Safety System, International Maritime Organization, ISBN 978-92-801-1660-1, 2017, London

[2] Rokseth B.; Utne I.B. \& Vinnem J.E. (2017). A systems approach to risk analysis of maritime operations, Proceedings of the Institution of Mechanical Engineers Part O-Journal of Risk and Reliability, ISSN: 1748006X, Terje Aven (Ed.), 231(1): pp 53-68, Sage publications Ltd, London, DOI: 10.1177/1748006X16682606

[3] Xi Y.T. \& Yang Z.L.; Fang Q.G.; Chen W.J.; Wang J. (2017). A new hybrid approach to human error probability quantification-applications in maritime operations, Ocean Engineering, Vol. 138, pp 138:45-54, ISSN: 0029-8018, DOI:10.1016/j.oceaneng.2017.04.018

[4] Molland T., Maritime Engineering Reference Book: A Guide to Ship Design, Construction and Operation. Butterworth-Heinemann, ISBN: 9780750689878, Elsevier, 2008

[5] Lupu S.; Pocora A.; Nicolae F.; Katona C.; Lupu E.C. (2016). The Role of the Maritime Simulators in Evaluating the Practical Competencies of Graduated Students in Order to Accomplish Officer of the Watch Duties Onboard Vessels, Elearning Vision 2020, Vol I, 2016, pp 216-222, ISSN 2066-026X, DOI: 10.12753/2066-026X-16-031

[6] https://www.dnvgl.com, (2018) Det Norske Veritas Germanischer Lloyd, Accessed on: 2018-09-12

[7] Bielić T.; Vidan P. \& Mohović R. Complacency - major cause of maritime casualties, Pomorstvo, Vol. 24 No.2 (December 2010) pp 247-260, ISSN 1332-0718

[8] Corovic B \& Djurovic P. (2013). Research of Marine Accidents through the Prism of Human Factors, Promet Traffic and Transportation, Zagreb. Vol. 25 No. 4. pp 369-377, ISSN 0353-5320, DOI 10.7307/ptt.v25i4.1210

[9] Celik M. \& Cebi S. (2009). Analytical HFACS for investigating human errors in shipping accidents, Accident Anal Prevention, Vol. 41 No.1, pp 66-75, ISSN 0001-4575, DOI 10.1016/j.aap.2008.09.004

[10] Akyuz E. (2017). A marine accident analysing model to evaluate potential operational causes in cargo ships, Safety Science, Vol. 92. pp 17-25, ISSN 0925-7535, DOI 10.1016/j.ssci.2016.09.010

[11] Wagenaar W.A. \& Groeneweg J. (1987). Accidents at Sea - Multiple Causes and Impossible Consequences, International Journal of Man-Machine Studies. Vol. 27, No. 5-6. pp 587-598, ISSN 0020-7373, DOI 10.1016/S00207373(87)80017-2 
[12] Zhao J.N. \& Lv J. (2016). Comparing prediction methods for maritime accidents, Transport Planning and Technology, Vol. 39, No. 8. pp 813-825, ISSN 0308-1060, DOI 10.1080/03081060.2016.1231901

[13] Wu B.; Yan X.P.; Wang Y.; Soares C.G. (2017). An Evidential Reasoning-Based CREAM to Human Reliability Analysis in Maritime Accident Process. Risk Analysis, Vol. 37, No. 10. pp 1936-1957, ISSN 0272-4332 DOI 10.1111/risa.12757

[14] Chauvin C.; Lardjane S.; Morel G.; Clostermann J.P.; Langard B. (2013). Human and organisational factors in maritime accidents: Analysis of collisions at sea using the HFACS, Accident Analysis \& Prevention, Vol. 59. pp 26-37 ISSN 0001-4575, DOI 10.1016/j.aap.2013.05.006

[15] Liu, X. W.; Xiao, F. B. \& Jin, Y. C (2009). A Prototype of Marine Search and Rescue Simulator, International Conference on Information Technology and Computer Science, Vol 1, Proceedings, 2009: pp 343-346, ISBN: 9780-7695-3688-0, DOI 10.1109/Itcs.2009.291

[16] Soner O.; Asan U. \& Celik M. (2015). Use of HFACS-FCM in fire prevention modelling on board ships, Safety Science, Elsevier, Vol. 77. pp 25-41, ISSN 0925-7535, DOI 10.1016/j.ssci.2015.03.007

[17] Ozdemir U.; Guneroglu A. (2015). Strategic Approach Model for Investigating the Cause of Maritime Accidents. Promet - Traffic and Transportation, Zagreb. Vol. 27. No 2. pp 113-123, ISSN 0353-5320, DOI $10.7307 /$ ptt.v27i2.1461

[18] Mu L. \& Prinz A. (2012). Delay-oriented data traffic migration in maritime mobile communication environments, Fourth International Conference on Ubiquitous and Future Networks (ICUFN), Phuket, Thailand, 4-6 July 2012. IEEE, ISBN 2165-8528, DOI 10.1109/ICUFN.2012.6261741

[19] Mu L.P.; Prinz A. \& Reichert F. (2013). Towards Integrated Operations for Ships, 9th International Wireless Communications and Mobile Computing Conference (Iwcmc). pp 941-946, ISSN 2376-6492, DOI 10.1109/IWCMC.2013.6583683

[20] Hanzu-Pazara R.; Barsan E.; Arsenie P.; Chiotoroiu L.; Raicu G. (2018). Reducing of maritime accidents caused by human factors using simulators in training process, Journal of Maritime Research, SEECMAR Vol. 5, No 1. pp 318, ISSN 1697-9133

[21] Wooldridge M. \& Jennings N.R. (1995). Intelligent Agents - Theory and Practice, Knowledge Engineering Review, Cambridge University Press, Vol. 10, No. 2. pp 115-152, ISSN 0269-8889, DOI 10.1017/S0269888900008122

[22] Sterling L. \& Taveter K. (2009). The art of agent-oriented modelling, The MIT Press, ISBN 9780262013116. xix, $367 \mathrm{p}$, Cambridge, MA

[23] Vercouter L.; Beaune P.; Sayettat C. (2000). Towards open distributed information systems by the way of a multiagent conception framework, Working Notes of the AAAI-2000 Workshop on Agent-Oriented Information Systems (AOIS-2000), Austin, United States, HAL Id : emse-00854283, version 1

[24] van der Hoek W. \& Wooldridge M. (2012). Logics for Multiagent Systems, Ai Magazine, Vol. 33, No. 3, pp 92105, ISSN 0738-4602, ISI:000309621600008

[25] Chen B. \& Cheng H.H. (2010). A Review of the Applications of Agent Technology in Traffic and Transportation Systems. IEEE Transactions on intelligent transportation systems, IEEE, Vol. 11, No. 2. pp 485-497, ISSN 15249050, DOI 10.1109/Tits.2010.2048313

[26] Rob A. (2010). A survey of agent based modelling and simulation tools, Technical Report DL-TR-2010-07, Science and Technology Facilities Council, ISSN 1362-0207

[27] Ha J.S. (2014). A Soft Control Model for Human Reliability Analysis in APR-1400 Advanced Control Rooms (ACRs). Procedia Engineering, Proceedings of 25th DAAAM International Symposium on Intelligent Manufacturing and Automation, B. Katalinic (Ed.), DAAAM 2014, Vienna, 26th to 29th November 2014, 2015;100:24-32., DOI: 10.1016/j.proeng.2015.01.338

[28] Shumsky, A.; Zhirabok, A. \& Kalinina, N. (2017). Human-Operator Behaviour Monitoring in IT-Systems, Proceedings of the 28th DAAAM International Symposium, pp.0160-0167, B. Katalinic (Ed.), Published by DAAAM International, ISBN 978-3-902734-11-2, ISSN 1726-9679,Vienna, Austria, DOI: 10.2507/28th.daaam.proceedings.021 